\title{
Chapter 15 \\ Economic Context and Attitudes towards the Welfare State: The Relationship between (Perceived) Unemployment Risk and Demand for Social Policy
}

\author{
Nicolas Pekari, Jan Rosset, and Flurina Schmid
}

\section{Introduction}

Preferences regarding the welfare state and redistributive policies have attracted much scholarly attention in the past decades (Lupu and Pontusson 2011; Svallfors 2012). One of the main reasons is that these preferences are expected to influence individuals' electoral choices and thus impact public policy. Therefore, they are seen as crucial for understanding cross-country differences or temporal evolution in the shape or size of welfare states in democracies (Meltzer and Richard 1981; Svallfors 1997). Individual preferences are also expected to be shaped by a potentially changing context. Changing levels of inequality or changing levels of unemployment rates for instance should in theory influence the size and composition of groups potentially benefitting from or contributing to the welfare state and thus shape the incentive of favouring certain type of policy (Meltzer and Richard 1981; Rehm 2009). However, most of the studies on the topic have analysed the influence of the context across countries rather than over time and those that look at the evolution of attitudes towards the welfare state within specific countries have focused mainly on Anglo-Saxon countries. These studies tend to show a rather limited impact of a changing context on preferences, even in times of a dramatic change of economic conditions such as the recent Great Recession (Brooks and Manza 2013; Margalit 2013; Soroka and Wlezien 2014). ${ }^{1}$

\footnotetext{
${ }^{1}$ See however Rosset and Pontusson (2014) who document a trend for an increased demand for redistribution among middle income groups in those western European countries that were most severely hit by the crisis.

N. Pekari $(\varangle) \cdot$ F. Schmid

FORS-Swiss Centre of Expertise in the Social Sciences, Lausanne, Switzerland

e-mail: nicolas.pekari@fors.unil.ch

J. Rosset

University of Geneva, Geneva, Switzerland

e-mail: jan.rosset@unige.ch
} 
Although economic conditions have not changed in Switzerland as much as in many other European countries during the Great Recession (Ball 2014; OECD $2013 \mathrm{a}, \mathrm{b})$, this case is relevant for the study of the evolution of public opinion regarding the welfare state. Indeed, Swiss direct democratic institutions allow civil society actors to put new topics on the agenda (popular initiative) or to oppose decisions taken by representatives by organising popular votes on specific bills. This means that citizens regularly vote on specific policies and that public opinion is thus likely to be particularly influential. Another interesting factor is the rise, over the last two decades, of a right-wing populist party, the Swiss People's Party (SVP), which has almost tripled its vote share since the early 1990's and moved the position of Swiss representative bodies more towards the right of the political spectrum. While this could itself be a sign of a shift of Swiss public opinion away from the welfare state, the situation might be more ambiguous because this electoral shift is concomitant with an increased importance of non-economic issues in Swiss electoral politics, with notably issues such as immigration or European integration becoming more salient (Bornschier 2015). Given that citizens' preferences on those cultural issues do not correlate with their stances on economic issues (Rosset et al. 2016) and the rise of importance of the former set of issues, it cannot be assumed that economic preferences of the Swiss are directly reflected in their electoral choice. It is therefore particularly interesting to explore how Swiss public opinion has evolved on issues related to social policy since the turn of the millennium.

For the period from 1999 to 2014, the Swiss household panel (SHP) provides individual level data on preferences with regard to several dimensions of the welfare state and include measures of risk perception which is relatively rare for generalist surveys. Making use of this data, the goal of this chapter is, on the one hand, to describe the evolution of political attitudes towards the welfare state of Swiss residents over the 1999-2014 period and, on the other hand, to test some of the theories explaining opinion formation at the individual level.

Our analyses show that overall levels of public support for social policy have not dramatically changed. There has been, however, a shift in the nature of policies that attract more support and meaning that the level of support for social spending and for more progressive taxation is quite different in 2014 as it used to be 15 years earlier. On the one hand there has been an increase in the share of Swiss residents calling for higher taxes on high incomes, but on the other hand, a decrease in support for social spending. The decrease in support for social spending seems at odds with the fact that an increasing proportion of Swiss feel at risk of losing their job. We explain this apparent contradiction to our finding that individual preferences are relatively weakly affected by changing economic conditions.

We focus on attitudes towards unemployment benefits to show that whereas objective levels of risk are associated with preferences towards unemployment benefits, the relationship between one's risk profile and preferences is mainly a result of structural factors such as education or economic status. The role of deeply rooted social structures for the preferences regarding unemployment benefits suggests that 
changes in economic conditions and unemployment rates in particular are likely to only partially translate into citizen's preferences.

The chapter is structured as follows: the next section discusses the literature on the welfare state and on the Swiss political context. We then turn to an analysis of overall trends in support for levels of taxation for the rich and social spending and relate these trends to changes in the level of perceived economic insecurity. The next section is devoted to an individual-level analysis that focuses on the relationship between objective economic conditions to policy preferences by addressing the link between objective and perceived risk and then perceived risk and preferences for redistribution. The remainder of the chapter discusses the results and concludes.

\section{Preferences for the Welfare State and the Role of the Economic Context}

Attitudes towards the welfare state have been extensively studied using various sources of survey data. While early research has mainly focused on general support for the welfare state (or redistribution) and on the role of individuals' economic status in explaining their preferences, recent studies have brought several refinements. First, it appears that preferences towards the welfare state cannot be summarized simply in terms of support or opposition towards the welfare state but that they vary in relation to different dimensions of the welfare state. Being in favour of a specific social policy - say unemployment benefit - does not mean that individuals will also endorse other facets of the welfare state such as for instance health insurance or pensions. In addition to support for specific areas of the welfare state, the public seems to have quite contrasted views on two different but complementary aspects of social policies. These can be primarily understood on the one hand as ways of taking economic means "from the rich" or, on the other hand, as ways of "giving them to the poor" (Cavaillé and Trump 2015). Support for each of these aspects of the welfare state can be explained by different individual characteristics and the study of social policy attitudes needs to take both of these facets into account. Second, it appears that even if self-interest plays a role in the formation of preferences with regard to social policy, the definition of this self-interest is multifaceted also. To put it simply, individuals do not simply differ in terms of their income levels, but also in terms of for instance the risk of losing their job, the type of private insurance they would get would they lose their jobs and so on. Consequently all those characteristics are to be taken into account in order to understand individuals' rationale to support the welfare state. Whereas previously the political economy literature based its theories on class and income (Esping Andersen 1990; Korpi 1983; Meltzer and Richard 1981) to explain welfare state support, a more recent focus, developed as a counterargument to the first literature, has been on economic risk (Cusack et al. 2008; Iversen and Soskice 2001). 
The global financial crisis has made this line of work particularly relevant. At its wake, there is more unemployment, temporary and involuntary part-time work, and financial insecurity (OECD 2013a). However, economic insecurity is not a new concern. As shown by Hacker et al. (2013) for the US, economic insecurity has seen a steady rise starting from the mid-1980s, affecting practically all population groups. Many authors have also commented on the modern labour market bringing increased employment instability and growing job insecurity (Anderson and Pontusson 2007; Dekker 2010). It can also be argued that the welfare state has always been most effective in insuring against risk and that this has been its main objective all along, rather than redistribution (Esping-Andersen 1999). Though lower-income individuals tend to also have a higher risk of becoming unemployed, this correlation depends on the country and the policy domain, and there is a substantial amount of individuals that are cross-pressured (Rehm et al. 2012). Thus income alone cannot satisfactorily resume both the redistributive and insurance aspect of the welfare state.

These changes in the labour-market have also affected Switzerland where the combined share of individuals who are unemployed or precariously employed (temporarily and involuntary part-time) amounted to about $15 \%$ already before the financial crisis of 2007-8, which is not much lower than the OECD average at the time (Rueda 2012). While intuitively it seems that high level of insecurity should be associated with a higher demand for an insurance against economic risk and thus demand for social policy, this cannot be taken for granted because of labour market dualization. Some groups (labour market insiders) remain largely unaffected by unemployment risk and might see high levels of insecurity chiefly through the prism of increased social expenses and others, even if they face high level of insecurity, might fall outside of the scope of the traditional instruments of the welfare state and therefore not be particularly supportive of social policies which they see as particularly benefitting the insiders.

The question therefore remains open as to whether employment insecurity is associated with higher demand for social protection. There are indeed a two requirements for structural changes in the labour market to impact demand for social policy. First, it is only if the public actually perceives a higher risk that objective risk can matter for public opinion. Second, this perceived risk needs to translate into policy preferences, which means that individuals update their demand for social policy based on their assessment of risk. The latter implies individual preferences are very flexible.

\section{Ever More Mittelstand? Preferences that Reflect an Anti-Rich and Anti-Poor Sentiment}

In order to analyse citizens' perception of their economic risk and their preferences for social policy we focus on three different questions asked in the Swiss Household Panel which have been included in the survey since 1999 annually until 2009 and 
from then on in an interval of 2 or 3 years. The three questions relate to citizen's perception of unemployment risk ("How do you evaluate the risk of becoming personally unemployed in the next 12 months?" on a scale from 0 to 10 , where 0 means "no risk at all" and 10 stands for "a real risk"), their preferences with regard to higher taxation of the rich ("Are you in favour of an increase or in favour of a decrease of the tax on high incomes?" With the three answer categories being: ,in favour of an increase", "in favour of a decrease" and "neither"), and increased spending for social security ("Are you in favour of a diminution or in favour of an increase of the Confederation social spending?" With again three answer categories). These variables have been recoded in order to obtain the share of respondents who do feel at least some degree of unemployment risk (i.e. have not answered 0 on the scale), and those who favour increased taxation for the rich and increased social spending respectively. ${ }^{2}$

Figure 15.1 shows the development of opinions over time. A striking observation is the concomitant rise of perceived unemployment risk with the decreasing trend of support for social spending. In the three first years about $45 \%$ of respondents felt they were to some extent threatened by unemployment and around the same share favoured increased social spending. Since 2001, the two lines follow opposed trends and in the post-financial crisis period the gap between the share of respondents

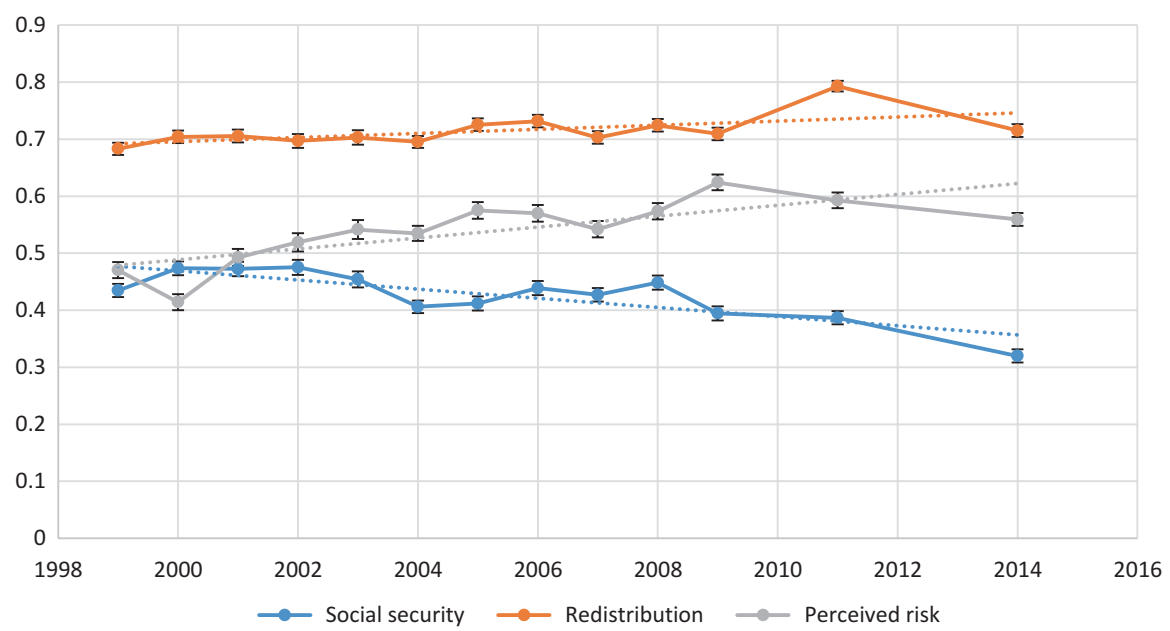

Fig. 15.1 Perceived unemployment risk and attitudes towards redistribution and social security over the 1999-2014 period, based on data from the Swiss Household Panel

\footnotetext{
${ }^{2}$ In these analyses data from all three SHP samples and cross-sectional weights are used. Note that when restricting the analysis only to respondents who participated in the SHP since 1999 and making use of longitudinal weights similar trends appear suggesting that shifts in the opinions of the Swiss is not merely due to composition effects or generational change.
} 
feeling threatened and those who support increased social protection has amounted to around $20 \%$ points. Not only has the perception of risk increased with around 6 in 10 Swiss residents not feeling completely safe about their jobs, but the share of respondents favouring increased social spending has dropped below $40 \%$ since 2009.

Interestingly, the level of support for increased taxation of the rich has remained rather stable over the same period or even slightly increased from already very high levels in 1999. The high-point of this shift coincides with the aftermath of the financial crisis. In 2009, almost $80 \%$ of SHP respondents favoured increasing taxes for the rich. While the share has slightly decreased afterwards it appears that the general trend in relation to redistribution is a rising one. To borrow Cavaillé and Trump's (2015) terminology "redistribution from the rich" enjoys high and potentially even increasing levels of support while support for "redistribution to the poor" has declined since the end of millennium from already relatively low levels. How to interpret these trends?

The high level of support for increased taxation for the rich might show the inequality-averse preferences of the Swiss. But these opinions seem to be particularly oriented against reducing the post-tax income gap at the top of the income distribution rather than increasing state intervention in favour of those located towards the lower end of the income distribution. This trend is surprising given the overall increase of perceived job insecurity and thus the potential for having to resort to the welfare state. Of course one potential explanation could be that individuals do not feel sufficiently threatened by economic risk to favour increased state intervention from which they will unlikely benefit, but this observed paradoxical trend between overall level of perceived risk and preferences for social protection calls for a closer analysis of the causal chain linking economic conditions to individual preferences. To what extent does the objective economic situation of an individual impact his or her perception of that situation? And to what extent does this perceived situation impact their policy preferences? Studying this relationship is precisely the goal of the next section which proposes an individual-level analysis of attitudes towards unemployment benefits specifically.

\section{Individual-Level Analysis: The Link between Objective Unemployment Risk, Perceived Risk and Demand for Social Protection}

In order to analyse the micro-foundations of the link between objective risk of unemployment, the perception of this risk and finally demand for more protection in the specific domain of unemployment benefit, we rely on SHP data from the year 2011 which includes all variables of interest and for which unemployment figures across occupations were available. We focus on objective risk as defined by the level of unemployment in one's occupation - a common measure of objective 
unemployment risk using data from the Federal Statistical Office. Given our focus on unemployment risk, we restrict the sample to the active population who are the only ones who might be directly impacted.

Our analysis relies on two distinct steps. In a first step, we assess whether the Occupational Unemployment Rate is indeed associated with the perception of unemployment risk. In a second step we analyse the link between occupational unemployment rate and policy preferences regarding unemployment policies. More precisely, we are interested in assessing to what extent this link is mediated by one's perception of risk and to what extent mediated by other factors - in particular education and income - that might also affect the relationship.

Our empirical strategy implies having two dependent variables corresponding to the two stages of the analyses. The first one is perceived unemployment risk which has been measured using the same question as the one presented above ${ }^{3}$.

The dependent variable in our second set of models is respondent's preferences with regard to unemployment benefits. Here, we use a specific question on whether spending for unemployment benefits should be increased, decreased or kept at its current level ${ }^{4}$. As is often done in studies on redistributive policies we recode this 3-category variable into a dummy variable distinguishing between those who favour an increase in unemployment benefit spending (coded 1) and those who either support a cut or favour a status quo (both coded 0 ), the latter de facto corresponding to an opposition of an increase in unemployment benefits.

The focus independent variable in both analyses is the Occupational Unemployment Rate (OUR). This has been created using data from the Swiss Labour Force Survey conducted in 2011 which includes about 30'000 individuals and allows computing average unemployment rates per occupation. We have computed these measures for each of the ISCO-2 digit occupations documented in the survey and matched these OUR measures with individuals based on their occupation. This measure corresponds very closely to what unemployment occupational risk has been operationalized in the literature so far (see Rehm 2009).

Our models further include a series of control variables that can be classified into two main categories: sociodemographic variables and individual characteristics that are associated with the economic self-interest of respondents. Among variables that belong to this second subset, we include the yearly net income at the individual level. We also include a variable measuring relative skill specificity. For this variable, we used data that is made available by Torben Iversen on his website and provides skill specificity measures that have been computed based on the ISSP surveys. This variable measures how specific one's skills are and should therefore

\footnotetext{
${ }^{3}$ To recall: "How do you evaluate the risk of becoming personally unemployed in the next 12 months?" on a scale from 0 to 10 , where 0 means no risk at all and 10 stands for a real risk.

${ }^{4}$ Note that we measure here whether respondents are in favour of increasing spending on unemployment benefits specifically in contrast to the more general question presented in the previous section. The exact wording of the question used in the individual-level analysis is the following: "The government spends money in different sectors. Could you please tell me, for the following sectors, if you wish the government would spend more, less or the same amount? “
} 
capture how difficult it is for a person to find a job that makes use of these specific skills in case of job loss (see Cusack et al. 2006; Iversen and Soskice 2001). Whether one has a temporary or long term working contract, thus whether a person is a labour market outsider or insider (see Rueda 2007), is measured with a dummy variable $(0=$ unlimited contract; $1=$ temporary contract $)$. We further include a control variable that measures previous unemployment experience (coded 1 for all those who reported having been unemployed in the past and zero otherwise). Furthermore, we also control for the number of earners in a household by distinguishing between individuals who are the only wage earners in their household (coded 0) and those who live with at least one other wage earner (coded 1). The underlying idea is that the consequences of unemployment on one's financial situation are tougher if that person is the only wage earner in the household.

The sociodemographic control variables includes age (measured as a metric variable), gender ( $0=$ man; $1=$ woman $)$, education (a three category variable in which the reference category is no or only compulsory education; the other two categories being "above compulsory" and "tertiary" education). We also add a dummy variable for region which controls for all the observed and unobserved regional characteristics of the 7 Swiss regions as defined by the Swiss Federal Statistical Office (corresponding to the NUTS-2 level). In some of the models we further include a variable measuring social class. For this we use Oesch's class scheme which includes 8 different categories: Self-employed professionals and large employers, small business owners, (associate) managers and administrators, office clerks, technical professionals and technicians, production workers, socio-cultural (semi-)professionals and service workers. According to its author, this class scheme captures social stratification in modern societies, taking also account of the deindustrialization, the welfare state expansion, and the increased participation of women in the labor market. The focus is not only on hierarchical divisions but also on horizontal cleavages to reflect better the heterogeneity of today's middle class (Oesch 2006).

As the two dependent variables in our models have different measurement levels, we use an OLS regression to model perceived unemployment risk (which is measured with a11 point scale) and a logistic regression for the model in which preferences for unemployment benefits represent the dependent variable coded as a dummy. In addition to these analyses, we perform a product of coefficients test for the second set of models. This enables us to estimate how much of the relationship is mediated by perceived unemployment risk and how much by the socioeconomic factors we focus on: education and income. This test is similar to the Sobel test (Baron and Kenny 1986; Sobel 1982), used to determine mediation effects. ${ }^{5}$

\footnotetext{
${ }^{5}$ Note, however, two important differences in our approach. First, as our dependent variable is dichotomous, it is necessary to standardize the coefficients before doing the calculations (for more details, see MacKinnon and Dwyer 1993). We use a user written Stata command called binary mediation to achieve this. Second, we use bootstrapping to calculate standard errors and significance levels, which are not given by the binary_mediation command. This has also been proven to be a superior approach, especially when not working with very large samples (Preacher and Hayes 2008).
} 
15 Economic Context and Attitudes towards the Welfare State: The Relationship...

Table 15.1 OLS regression models predicting perception of unemployment risk

\begin{tabular}{|c|c|c|c|c|c|}
\hline & & Model 1 & Model 2 & Model 3 & Model 4 \\
\hline $\begin{array}{l}\text { Occup. Unemp. } \\
\text { Rate }\end{array}$ & & $0.299 * * *$ & $0.281 * * *$ & $0.238 * * *$ & $0.233 * * *$ \\
\hline Skill specificity & & $0.338 * * *$ & $0.369 * * *$ & $0.421 * * *$ & $0.396 * * *$ \\
\hline Contract type & Fixed & $-1.157 * * *$ & $-1.432 * * *$ & $-1.541 * * *$ & $-1.521 * * *$ \\
\hline $\begin{array}{l}\text { Net income } \\
\left(10^{\prime} 000 \mathrm{~s}\right)\end{array}$ & & -0.015 & $-0.049 * * *$ & $-0.064 * * *$ & $-0.058 * * *$ \\
\hline Past unemployment & Yes & & & & $0.628 * * *$ \\
\hline Number of earners & $>1$ & & & & $-0.221 * *$ \\
\hline \multirow[t]{6}{*}{ Region (GE Lake) } & Middleland & & $-0.715^{* * *}$ & $-0.728 * * *$ & $-0.646 * * *$ \\
\hline & North-west & & $-0.745 * * *$ & $-0.725 * * *$ & $-0.653 * * *$ \\
\hline & Zurich & & -0.200 & -0.209 & -0.135 \\
\hline & East & & $-0.871 * * *$ & $-0.863 * * *$ & $-0.744 * * *$ \\
\hline & Central & & $-0.763 * * *$ & $-0.795 * * *$ & $-0.717 * * *$ \\
\hline & Ticino & & -0.265 & -0.329 & -0.324 \\
\hline Gender & Female & & 0.0389 & 0.0782 & 0.0713 \\
\hline Age & & & $0.0282 * * *$ & $0.0300 * * *$ & $0.0307 * * *$ \\
\hline \multirow[t]{2}{*}{ Education (low) } & Middle & & & $0.282 *$ & 0.238 \\
\hline & High & & & 0.196 & 0.116 \\
\hline \multirow[t]{7}{*}{$\begin{array}{l}\text { Class (self-emp } \\
\text { prof) }\end{array}$} & $\begin{array}{l}\text { Small business } \\
\text { owners }\end{array}$ & & & $-1.321 *$ & $-1.159 *$ \\
\hline & $\begin{array}{l}\text { Managers and } \\
\text { admins }\end{array}$ & & & -0.0896 & 0.0156 \\
\hline & Office clerks & & & -0.325 & -0.175 \\
\hline & Tech professionals & & & -0.203 & -0.0683 \\
\hline & $\begin{array}{l}\text { Production } \\
\text { workers }\end{array}$ & & & -0.441 & -0.25 \\
\hline & $\begin{array}{l}\text { Socio-cultural } \\
\text { profs }\end{array}$ & & & -0.739 & -0.59 \\
\hline & Service workers & & & -0.309 & -0.154 \\
\hline Constant & & $3.173 * * *$ & $2.972 * * *$ & $3.263 * * *$ & $3.374 * * *$ \\
\hline $\mathrm{N}$ & & 2112 & 2112 & 2112 & 2105 \\
\hline R-squared & & 0.069 & 0.106 & 0.116 & 0.124 \\
\hline
\end{tabular}

$* * * \mathrm{p}<0.01, * * \mathrm{p}<0.05, * \mathrm{p}<0.1$

In Table 15.1, we find in the first model with only the four objective variables related to the theories on risk: OUR, skill specificity, contract type (insider/outsider status), and income that all except the last are highly significant predictors of perceived unemployment risk with the relationships working in the expected direction. The relationships remain, and become significant for income, when controlling for basic sociodemographics in model 2 , social class in model 3 , and past unemployment and number of earners in model 4. This seems to show that these objective measures, and namely OUR, do capture something that people are aware of and can be used as a way of measuring the insecurity one feels at her or his workplace. 
Table 15.2 Logistic regression models predicting being in favour of increased unemployment spending

\begin{tabular}{|c|c|c|c|c|c|}
\hline & & Model 1 & Model 2 & Model 3 & Model 4 \\
\hline OUR & & $0.115^{* * *}$ & $0.0935 * * *$ & 0.0591 & 0.0462 \\
\hline Risk perception & & & $0.105 * * *$ & & $0.0855^{* * *}$ \\
\hline Income $\left(10^{\prime} 000 \mathrm{~s}\right)$ & & & & $-0.087 * * *$ & $-0.080 * * *$ \\
\hline \multirow[t]{2}{*}{ Education (low) } & Middle & & & $-0.418 * * *$ & $-0.398 * * *$ \\
\hline & High & & & $-0.401 * *$ & $-0.371^{*}$ \\
\hline \multirow[t]{6}{*}{ Region (GE Lake) } & Middleland & $-0.463^{* * *}$ & $-0.398 * * *$ & $-0.500 * * *$ & $-0.443 * * *$ \\
\hline & North-west & $-0.826^{* * *}$ & $-0.770 * * *$ & $-0.908 * * *$ & $-0.866 * * *$ \\
\hline & Zurich & $-0.779 * * *$ & $-0.765 * * *$ & $-0.806 * * *$ & $-0.802 * * *$ \\
\hline & East & $-0.829 * * *$ & $-0.763 * * *$ & $-0.942 * * *$ & $-0.886^{* * *}$ \\
\hline & Central & $-0.799 * * *$ & $-0.732 * * *$ & $-0.796 * * *$ & $-0.744 * * *$ \\
\hline & Ticino & $0.621 * *$ & $0.616^{* *}$ & $0.769 * * *$ & $0.770 * * *$ \\
\hline Gender & Female & $0.302 * * *$ & $0.293 * * *$ & 0.0342 & 0.0525 \\
\hline Age & & $0.0214 * * *$ & $0.0199 * * *$ & $0.0314 * * *$ & $0.0293 * * *$ \\
\hline Constant & & $-2.353 * * *$ & $-2.616^{* * *}$ & $-1.207 * * *$ & $-1.498 * * *$ \\
\hline $\mathrm{N}$ & & 2680 & 2680 & 2506 & 2506 \\
\hline Pseudo R-squared & & 0.04 & 0.049 & 0.06 & 0.065 \\
\hline
\end{tabular}

$* * * \mathrm{p}<0.01, * * \mathrm{p}<0.05, * \mathrm{p}<0.1$

Depending on the model, the difference in perception of risk between workers in an occupation with the lowest and highest rates of unemployment is of between 1.4 and 1.8 points on an 11-point scale, a similar effect of that of having a temporary versus fixed contract. It should be pointed out that the R-squared, especially in the model with only the objective measures, is very low, indicating that there is much else determining one's perceived risk.

As expected, having been unemployed in the past increases worries among individuals, possibly making unemployment possibilities seem more real for. Not being the only earner in the household does also diminish somewhat the perceived risk, as expected.

There are relatively strong regional effects, which seem to reflect at least in part the fact that unemployment tends to be higher in French and Italian speaking regions, as well as in the canton of Zurich in the German speaking part of Switzerland. Older individuals also show a tendency towards a higher perceived risk, but no gender differences arise. Surprisingly, class, at least as operationalized here with the eight classes of Oesch (2006) has practically no effect, which goes against our suspicion that the OUR might confound somewhat with class differences.

In the second step, we ran four models predicting individual preferences for increasing unemployment spending (see Table 15.2). We find that in the first model with OUR and basic sociodemographic controls, the effect of the first on preferences is highly significant, as predicted by the theory. In the second model, we add risk perception. If OUR was completely mediated by the perceived risk, which seemed already unlikely given our first set of models, we would expect the effect of 


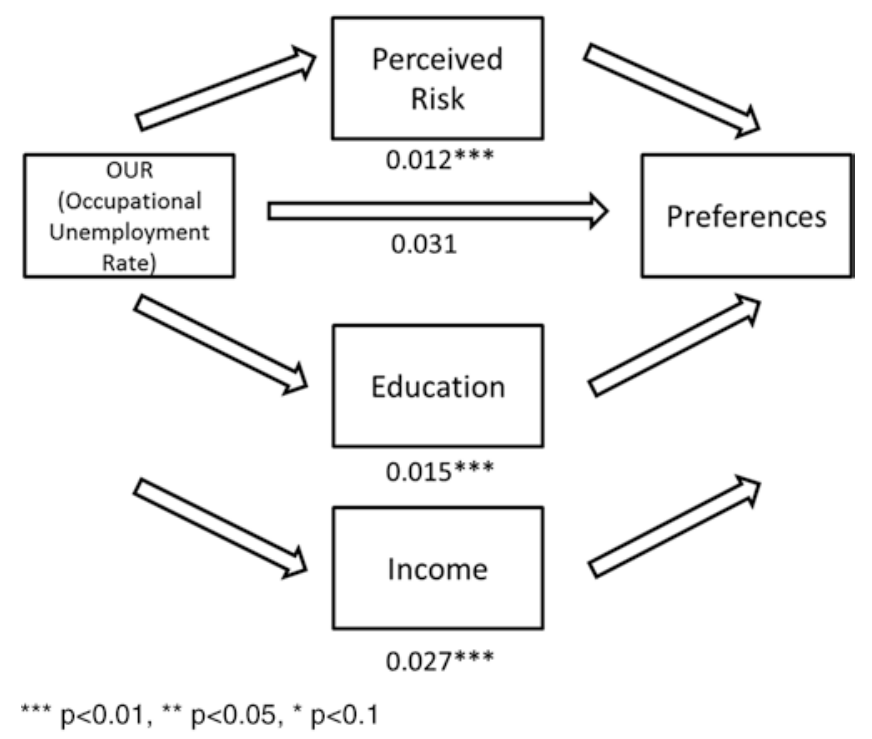

Fig. 15.2 Product of coefficients test: non-standardized direct and indirect effects. *** $\mathrm{p}<0.01$, $* * \mathrm{p}<0.05, * \mathrm{p}<0.1$

OUR to become non-significant. This does not happen, which tells us that both measure in part different things and influence individual preferences by different mechanisms.

In Model 3, we test our hypothesis of the effect of OUR on preferences being mediated by income and education, and find strong support. OUR becomes completely non-significant $(\mathrm{p}=0.122)$ when these two variables are added, thus hinting at a strong mediation effect. Both education and income are highly significant at predicting one's preferences regarding unemployment spending. Risk perception in turn remains significant with these variables added. Interesting again is the strong effect of regions, showing that expectations towards the welfare state are heterogeneous within Switzerland.

So as to better understand the mediation effects, we present in addition the results of a product of coefficients tests (Baron and Kenny 1986; MacKinnon and Dwyer 1993). In this test, five regression models are run, the resulting coefficients are standardized and, based on the latter, the effects of the different paths are calculated. The regressions comprise the five variables of interest: preferences regarding unemployment spending, OUR, perceived unemployment risk, education, and income. The variables are coded as in the models above. In all five models, we control for age, sex, and region. In Fig. 15.2, we show the resulting unstandardized effects of the three paths of interest. We use bootstrapping to calculate standard errors and the significance of the paths. Table 15.3 shows the rest of the results, namely the proportion of the total effect that is mediated by each of the three variables and the total direct and indirect effects. 
Table 15.3 Product of coefficients test: proportion of total effect mediated and total effects

\begin{tabular}{l|l}
\hline Proportion of total effect mediated: risk perception & 0.141 \\
\hline Proportion of total effect mediated: Education & 0.180 \\
\hline Proportion of total effect mediated: Income & 0.321 \\
\hline Proportion of total effect mediated: All & 0.642 \\
\hline Total indirect effect & $0.055^{* * *}$ \\
\hline Total effect & $0.086 * * *$ \\
\hline$* * * \mathrm{p}<0.01, * * \mathrm{p}<0.05, * \mathrm{p}<0.1$ &
\end{tabular}

As expected by the theory, we find that perceived risk significantly mediates the relationship between OUR and preferences $(\mathrm{p}<.01)$. However, this only represents about $14 \%$ of the total effect between OUR and preferences, which is relatively low compared to what we should find were this the main explanation for this effect. The size of the mediation effect by income is the same as that of risk perception but is not significant. Education in turn mediates the effect of OUR on preferences by $18 \%$ and is highly significant $(\mathrm{p}<.01)$. Income is highly significant and mediates as much as the two others combined, $32 \%$. The combined effect of both sociodemographic variables is 0.042 , more than three times that of risk perception. In total, they explain $50 \%$ of the total effect between OUR and preferences. A proportion of $64 \%$ of the total effect is mediated, the remaining direct effect being non-significant. This means that the two explanations proposed are likely to account for most of the relationship and no crucial component has been omitted from this analysis.

Our results indicate that individuals' perception of unemployment risk is to some extent linked to the unemployment rate in their occupation and that this link in part explains the relationship between the latter and policy preferences. However, we find that a more important explanation is related to the socioeconomic characteristics of individuals in a given occupation. We argue that this is because unemployment tends to be higher among individuals with low income and education levels. Thus occupations with higher unemployment rates tend to also to group together individuals with similar sociodemographic background. This means that belonging to a group more affected by unemployment will make the individual more inclined to support policies that help the unemployed, not so much out of self-interested calculations, but rather through a higher awareness of the issue, identification with those affected, and shared norms or solidarity (Svallfors 2006).

\section{Conclusion}

Preferences for social policy are expected to be influenced by a changing economic context. Individuals whose economic conditions or prospects evolve are generally expected to change their preferences because what they have to gain or lose from the welfare state also evolves over time. In line with this reasoning, times of increased economic insecurity should also lead to increased support for social policies because the odds of benefiting from them increases for the majority of the population. 
However, in the 1999-2014 period studied here, there is in Switzerland a paradoxical trend of an increased perception of economic risk, but a stable or even declining level of support for social spending, although levels of support for redistribution from taxing the rich more have remained relatively high.

In themselves these macro-level evolutions of public opinion are interesting as they show that there are different and independent components of support towards the welfare state (see e.g. Cavaillé and Trump 2015) and that Swiss residents have perceived a change in the level of unemployment insecurity. However, they also call for a closer examination of the link, at the individual level, between objective and subjective levels of risk subjective and social policy preferences which is at the heart of most theories linking economic conditions with public preferences.

The Occupational Unemployment Rate represents one of the main measures for assessing one's objective risk of unemployment. While previous studies have consistently shown a strong correlation between this indicator and individuals' preferences with regard to the welfare state, the mechanisms that would explain this association have rarely been tested. Yet, we argue, understanding these mechanisms is crucial for appreciating how, within a country or an occupation, changes in the level of unemployment might affect policy preferences. Is the relationship between occupational unemployment rates and preferences mediated via risk perception, in which case we could expect an increased level of unemployment to affect perception of risk and ultimately policy preferences? Or is it linked to the fact that the level of unemployment in one's occupation is itself associated with other more stable individual characteristics that will remain unaffected by shifts in macro-level unemployment in which case little change in public opinion can be expected even at times of rapid changes in levels of unemployment risk?

Based on data from the Swiss Household Panel survey, our individual-level analysis provides a nuanced answer to these pressing questions in the context of rising unemployment in Europe. On the one hand, it seems that individuals' perceived risk is to some extent determined by their objective level of risk of being unemployed (measured by Occupational Unemployment Rate), which provides evidence for the relevance of objective risk measures in the formation of social policy preferences. On the other hand, we find that a larger part of the association between occupational unemployment rate and policy preferences runs via education and income, characteristics that are relatively stable across time. As a result, our findings tend to challenge the view that changes in the level of unemployment rate would affect public opinion regarding social policies in general and unemployment benefits in particular. The recent rise in unemployment across industrialised countries greatly affects individuals' risk of losing their job. This rise might however not be followed by a rise in demand for more unemployment benefits due to the fact that deeply rooted social cleavages seem to account for much of the relationship between subjective evaluations of risk and social policy preferences.

While the findings presented show the relevance of studying the mechanisms that link objective measures of risk with policy preferences, they remain limited in scope and call for further analytical sophistication. By studying a single country, we are 
able to overcome some of the methodological limitations of previous studies, but at the same time restrict the generalizability of our results. Are the patterns we identify specific to a country with low levels of unemployment? Are they linked to the specific context of a rise of anxiety following the crisis that hit industrialized and particularly European countries after 2007? To answer these questions, more case studies conducted across a variety of nations and especially over time would certainly helpful. But this endeavour is limited by data availability, as few surveys include subjective measures of risk. In addition, the relevance of the research question that is addressed in this article clearly pertains to dynamic changes in the macro-economic context. However, our cross-sectional analysis does not allow to directly study the link between changes in the macro- (country) or meso- (occupation) levels of unemployment with policy preferences. Future research on that topic should ideally make use of longitudinal data at the individual-level in order to analyse how shifts in context affect individuals. Future waves of the SHP including individuals' perceptions of economic risk and their preferences with regard to unemployment benefits should allow for such analyses.

\section{References}

Anderson, C. J., \& Pontusson, J. (2007). Workers, worries and welfare states: Social protection and job insecurity in 15 OECD countries. European Journal of Political Research, 46(2), 211-235.

Ball, L. M. (2014). Long-term damage from the Great Recession in OECD countries. NBER working paper no. 20185: National Bureau of Economic Research.

Baron, R. M., \& Kenny, D. A. (1986). The moderator-mediator variable distinction in social psychological research: Conceptual, strategic, and statistical considerations. Journal of Personality and Social Psychology, 51(6), 1173.

Bornschier, S. (2015). The new cultural conflict, polarization, and representation in the Swiss party system, 1975-2011. Swiss Political Science Review, 21(4), 680-701. https://doi.org/10.1111/ spsr. 12180 .

Brooks, C., \& Manza, J. (2013). A broken public? Americans' responses to the great recession. American Sociological Review, 78(5), 727-748.

Cavaillé, C., \& Trump, K.-S. (2015). The two facets of social policy preferences. The Journal of Politics, 77(1), 146-160. https://doi.org/10.1086/678312.

Cusack, T., Iversen, T., \& Rehm, P. (2006). Risks at work: The demand and supply sides of government redistribution. Oxford Review of Economic Policy, 22(3), 365-389.

Cusack, T. R., Iversen, T., \& Rehm, P. (2008). Economic shocks inequality, and popular support for redistribution. In P. Beramendi \& C. J. Anderson (Eds.), Democracy, inequality and representation (pp. 203-231). New York: Russell Sage Foundation.

Dekker, F. (2010). Labour flexibility, risks and the welfare state. Economic and Industrial Democracy, 31(4), 593-611.

Esping Andersen, G. (1990). The three worlds of welfare capitalism. Princeton: Princeton University Press.

Esping-Andersen, G. (1999). Politics without class: Postindustrial cleavages in Europe and America. In Continuity and change in contemporary capitalism (pp. 293-316).

Hacker, J. S., Rehm, P., \& Schlesinger, M. (2013). The insecure American: Economic experiences, financial worries, and policy attitudes. Perspectives on Politics, 11(01), 23-49.

Iversen, T., \& Soskice, D. (2001). An asset theory of social policy preferences. American Political Science Review, 95(4), 875-893. 
Korpi, W. (1983). The democratic class struggle. London: Routledge and Kegan Paul.

Lupu, N., \& Pontusson, J. (2011). The structure of inequality and the politics of redistribution. American Political Science Review, 105(02), 316-336. https://doi.org/10.1017/S0003055411000128.

MacKinnon, D. P., \& Dwyer, J. H. (1993). Estimating mediated effects in prevention studies. Evaluation Review, 17(2), 144-158.

Margalit, Y. (2013). Explaining social policy preferences: Evidence from the great recession. American Political Science Review, 107(01), 80-103.

Meltzer, A. H., \& Richard, S. F. (1981). A rational choice theory of the size of government. The Journal of Political Economy, 89(5), 914-927.

OECD. (2013a). How's life? Paris: OECD Publishing.

OECD. (2013b). OECD employment outlook 2013. Paris: OECD Publishing.

Oesch, D. (2006). Redrawing the class map: Stratification and institutions in Germany, Britain, Sweden and Switzerland. London: Palgrave Macmillan.

Preacher, K. J., \& Hayes, A. F. (2008). Asymptotic and resampling strategies for assessing and comparing indirect effects in multiple mediator models. Behavior Research Methods, 40(3), 879-891.

Rehm, P. (2009). Risks and redistribution: An individual-level analysis. Comparative Political Studies, 42(7), 855-881.

Rehm, P., Hacker, J. S., \& Schlesinger, M. (2012). Insecure alliances: Risk, inequality, and support for the welfare state. American Political Science Review, 106(02), 386-406.

Rosset, J., \& Pontusson, J. (2014). The impact of the great recession on public preferences for redistribution in Western Europe. Paper presented at the APSA Washington.

Rosset, J., Lutz, G., \& Kissau, K. (2016). Representation of political opinions: Is the structuring pattern of policy preferences the same for citizens and elites? In M. Bühlmann \& J. Fivaz (Eds.), Political Representation. Roles, Representatives and the Represented (pp. 117-134). London: Routledge.

Rueda, D. (2007). Social democracy inside out: Partisanship and labor market policy in advanced industrialized democracies. New York: Oxford University Press.

Rueda, D. (2012). Dualization and crisis. Swiss Political Science Review, 18(4), 523-530.

Soroka, S., \& Wlezien, C. (2014). Economic crisis and support for redistribution in the United Kingdom. Mass Politics in Tough Times: Opinions, Votes and Protest in the Great Recession, 105.

Svallfors, S. (1997). Worlds of welfare and attitudes to redistribution: A comparison of eight western nations. European Sociological Review, 13(3), 283-304.

Svallfors, S. (2006). The moral economy of class: Class and attitudes in comparative perspective. Stanford: Stanford University Press.

Svallfors, S. (2012). Contested welfare states: Welfare attitudes in Europe and beyond. Stanford: Stanford University Press.

Sobel, M. E. (1982). Asymptotic confidence intervals for indirect effects in structural equation models. Sociological Methodology, 13, 290-312.

Open Access This chapter is licensed under the terms of the Creative Commons Attribution 4.0 International License (http://creativecommons.org/licenses/by/4.0/), which permits use, sharing, adaptation, distribution and reproduction in any medium or format, as long as you give appropriate credit to the original author(s) and the source, provide a link to the Creative Commons license and indicate if changes were made.

The images or other third party material in this chapter are included in the chapter's Creative Commons license, unless indicated otherwise in a credit line to the material. If material is not included in the chapter's Creative Commons license and your intended use is not permitted by statutory regulation or exceeds the permitted use, you will need to obtain permission directly from the copyright holder.

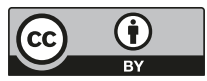

